\title{
Selective inhibition of proprotein convertases represses the metastatic potential of human colorectal tumor cells
}

\author{
Nathalie Scamuffa, ${ }^{1}$ Geraldine Siegfried, ${ }^{2}$ Yannick Bontemps, ${ }^{1}$ Liming Ma, ${ }^{3}$ Ajoy Basak, ${ }^{3}$ \\ Ghislaine Cherel, ${ }^{2}$ Fabien Calvo,1 Nabil G. Seidah,4 and Abdel-Majid Khatib1

\begin{abstract}
1INSERM U716, Equipe Avenir, Institut de Génétique Moléculaire, and Université Paris 7, Paris, France. ${ }^{2}$ INSERM U770, Université Paris-Sud, Faculté de Médecine Paris-Sud, IFR 93, Le Kremlin-Bicêtre, France. ${ }^{3}$ Regional Protein Chemistry Centre, Ottawa Health Research Institute,
\end{abstract} \\ Ottawa, Ontario, Canada. ${ }^{4}$ Laboratory of Biochemical Neuroendocrinology, Clinical Research Institute of Montreal, Montreal, Quebec, Canada.
}

\begin{abstract}
The proprotein convertases (PCs) are implicated in the activation of various precursor proteins that play an important role in tumor cell metastasis. Here, we report their involvement in the regulation of the metastatic potential of colorectal tumor cells. PC function in the human and murine colon carcinoma cell lines HT-29 and CT-26, respectively, was inhibited using siRNA targeting the PCs furin, PACE4, PC5, and PC7 or by overexpression of the general PC inhibitor $\alpha 1$-antitrypsin Portland ( $\alpha 1$-PDX). We found that overexpression of $\alpha 1-P D X$ and knockdown of furin expression inhibited processing of IGF-1 receptor and its subsequent activation by IGF-1 to induce IRS-1 and Akt phosphorylation, all important in colon carcinoma metastasis. These data suggest that the PC furin is a major IGF-1 receptor convertase. Expression of $\alpha 1$-PDX reduced the production of TNF- $\alpha$ and IL-1 $\alpha$ by human colon carcinoma cells, and incubation of murine liver endothelial cells with conditioned media derived from these cells failed to induce tumor cell adhesion to activated murine endothelial cells, a critical step in metastatic invasion. Furthermore, colon carcinoma cells in which PC activity was inhibited by overexpression of $\alpha 1-P D X$ when injected into the portal vein of mice showed a significantly reduced ability to form liver metastases. This suggests that inhibition of PCs is a potentially promising strategy for the prevention of colorectal liver metastasis.
\end{abstract}

\section{Introduction}

Although the liver is a common site for metastases from various forms of primary tumors, isolated hepatic metastases most commonly occur from colorectal cancer $(1,2)$. The hepatic resection for metastatic tumors from colorectal cancer remains the only curative option, and systemic or intra-arterial hepatic chemotherapy constitutes an alternative in some cases for patients with unresectable disease (1-4). However, the significance of hepatic resection for gastric metastasis has been controversial $(1,3)$. Thereby, better understanding of the cell and molecular biology of liver colorectal metastasis will facilitate the development of new efficient drugs and strategies that could supplement the conventional ones.

Cancer metastasis is a complex, dynamic process involving multiple interactions between the disseminating cancer cells and their rapidly changing microenvironments leading to the activation and/or expression of various molecules that initiate the establishment of metastasis. To successfully give rise to a liver metastatic colony, a cell or group of tumor cells must detach from the primary tumor, migrate, and invade the local host tissue. The formed lesion can itself become a disseminating cell source that gives rise to secondary and tertiary metastasis. These processes are mediated by molecular interactions resulting from deregulated expression and/or function of adhesion receptors, ECM-degrading proteinases, and growth-promoting factors and their receptors, thereby affecting cell-cell and cell-ECM communication. It is now well

Nonstandard abbreviations used: IGF-1R, IGF-1 receptor; PC, proprotein convertase; $R_{\mathrm{t}}$, retention time.

Conflict of interest: The authors have declared that no conflict of interest exists. Citation for this article: J. Clin. Invest. 118:352-363 (2008). doi:10.1172/JCI32040. established that the liver induction of cytokines and several adhesion molecules, particularly E-selectin, during interaction between liver cells and circulating colon cancer cells is one of the major early molecular events leading to liver colorectal metastasis (5-8). Compared with low metastatic or nonmetastatic colon cancer cells, only the arrest of highly metastatic ones in the hepatic circulation was found to cause this cascade of events. The latter start with a rapid release of several cytokines such as TNF- $\alpha$ and IL-1 that in turn stimulate the expression of E-selectin and other adhesion molecules on hepatic endothelial cells, leading to enhanced tumor cell adhesion in the liver (5-8). Subsequently, the survival and growth of metastatic cells following their adhesion is maintained by the overexpression and/or increased activity of other molecules such as IGF-1 receptor (IGF-1R) and its ligands IGF-1 and/or IGF-2 $(9,10)$. These molecules are frequently expressed in human colon cancers and have been implicated in the induction and maintenance of the malignant phenotype and in the control of cellular functions that impact on tumor angiogenesis, invasion, and metastasis, such as preventing apoptosis and enhancing cell proliferation (9-12). Previously, various studies reported that IGF-1 signaling, particularly the Akt pathway, was involved at each stage of cancer progression, including malignant transformation, tumor growth, and angiogenesis; local invasion; distant metastases; and resistance to various treatments (13).

The majority of proteins affecting the metastatic character of tumor cells, including colon cancer cells such as adhesion molecules, growth factors, growth factor receptors, and metalloproteinases, are synthesized as inactive precursor proteins that are converted to their bioactive forms by one or more of the 7 known kexin-like proprotein convertase (PC) family members, namely 


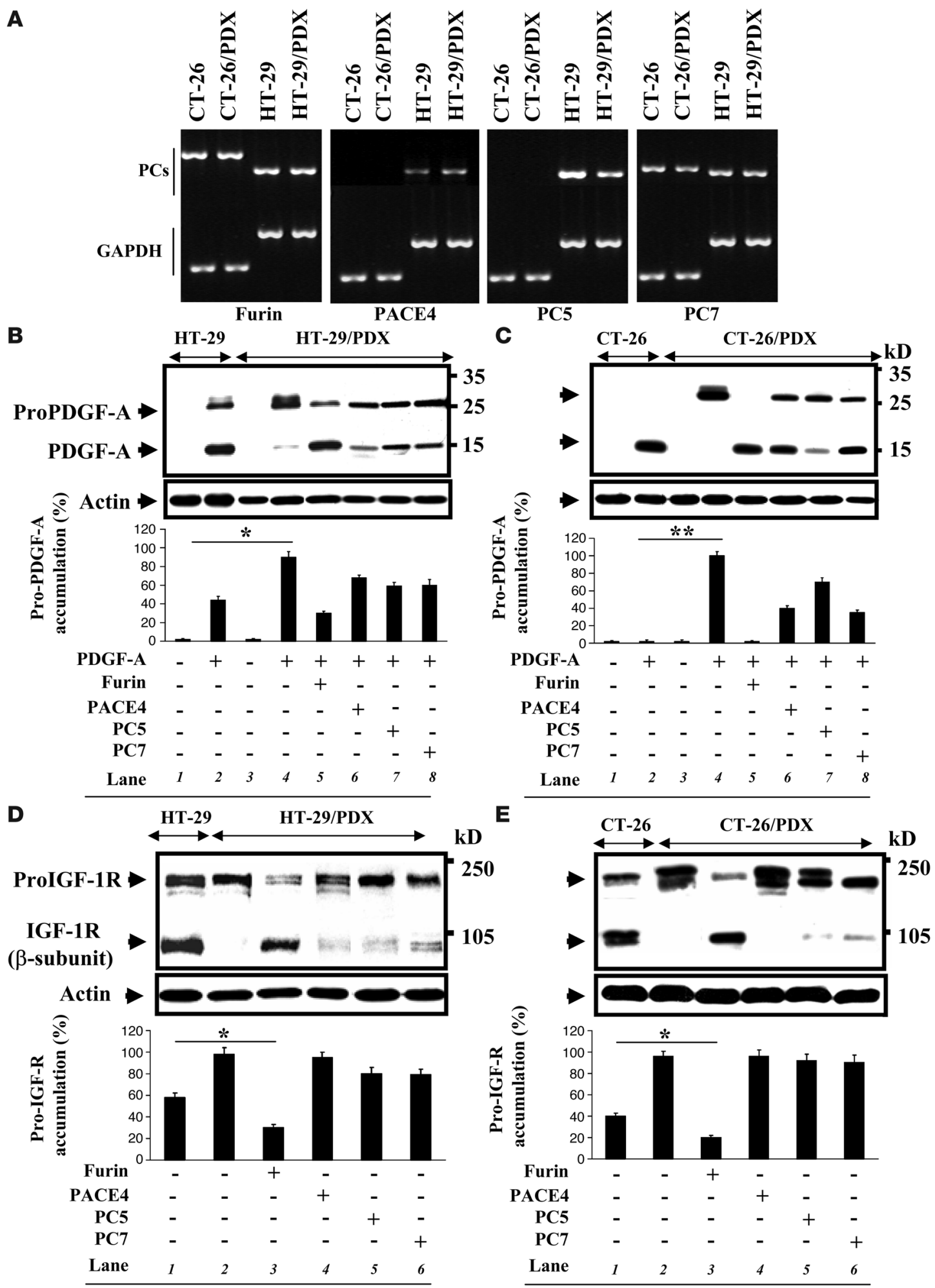

Figure 1

Inhibition of PC activity in HT-29 and CT-26 colon cancer cells. (A) RT-PCR analysis was performed on RNA extracted from the colon cancer cells HT-29 and CT-26 and the same cells that express the PC inhibitor $\alpha 1-P D X$ (HT-29/PDX and CT-26/PDX) using furin, PACE4, PC5, PC7, and GAPDH-specific primers. All these PCs were present in HT-26 and HT-29/PDX cells, whereas CT-26 and CT-26/PDX cells lacked the expression of PC5 and PACE4. (B-E) PDGF-A and IGF-1R processing was analyzed in the indicated cells by Western blotting using an anti-V5 (B and $\mathbf{C}$ ) and anti-IGF-1R antibody (D and E), respectively. Note that $\alpha 1-P D X$ inhibited the processing of these PC substrates, and only furin mediated complete rescue. Bars denote the corresponding percentages of pro-PDGF-A and pro-IGF-1R accumulation. Values are mean \pm SEM ( $n=3$ per group). ${ }^{*} P<0.005 ;{ }^{*} P<0.0002$. 

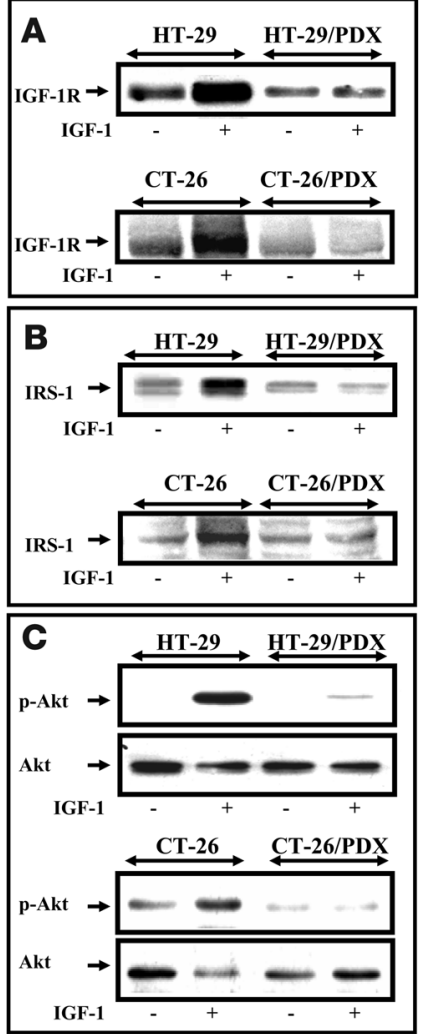

PC1, PC2, furin, PC4, PC5, PACE4, and PC7 (14-16). Previously, elevated levels of various convertases were reported to be associated with several cancers, and altered liver PC1 and PC2 expression was directly linked to liver colorectal metastasis (17). In this study we demonstrate the potential use of PCs as new targets in the treatment of liver colorectal metastasis through inhibition of the expression and/or activation of several proteins involved in early and late events required for liver colorectal metastasis.

\section{Results}

In hibition of $P C$ activity in colon cancer cells. To investigate whether the inhibition of PC activity in the colon carcinoma cells HT-29 and CT-26 will affect their ability to mediate PC substrate processing, we used the general PC inhibitor $\alpha 1$-PDX, which blocks the activity of all the PCs found in the secretory pathway - namely furin, PC5, PACE4, and PC7 - and siRNAs to knock down the expression of these PCs.

Using specific primers for furin, PACE4, PC5 and PC7, RT-PCR analysis revealed that while all these convertases were expressed in HT-29 cells and in HT-29 cells expressing $\alpha 1-P D X$ (HT-29/PDX cells), CT-26 and CT-26/PDX cells lacked the expression of PACE4 and PC5 (Figure 1A). To assess the inhibition of the PCs in HT-29/PDX and CT-26/PDX cells, we analyzed the processing of 2 PC substrates, PDGF-A (Figure 1, B and C) and IGF-1R (Figure 1, $\mathrm{D}$ and $\mathrm{E})$. These cells did not produce PDGF-A, whereas both cell lines expressed IGF-1R. PDGF-A is a good substrate that we used to analyze the endogenous activity of the PCs in these cells (18). Thereby, inhibition of proPDGF-A processing is a good indicator of lack of PC activity. Indeed, immunoblotting analysis of cell lysates derived from HT-29/PDX (Figure 1B) and CT-26/PDX (Figure 1C) cells transfected with a cDNA coding for proPDGF-A

\section{Figure 2}

PC blockade inhibits IGF-1-induced IGF-1R, IRS-1, and Akt phosphorylation. Serum-starved cells were stimulated for 10 minutes with $50 \mathrm{ng} / \mathrm{ml}$ IGF-1, and cell lysates were subjected to immunoprecipitation with either an anti-IGF-1R (A) or an anti-IRS-1 antibody (B). Immunoprecipitates were immunoblotted with anti-phosphotyrosine. (C) Cell lysates of IGF-1-activated cells were subjected to Western blotting with anti-phospho-Akt. The blots were stripped and reprobed with anti-actin or anti-Akt for data normalization. Results shown are representative of 3 experiments.

revealed that contrary to controls, these cells were unable to process significantly proPDGF-A, as demonstrated by the accumulation of its unprocessed form $(\sim 24 \mathrm{kDa})$ and the reduction of its mature form ( 15 kDa; Figure 1, B and C, lane 4). Expression of furin, PACE4, PC5, or PC7 in HT-29/PDX and CT-26/PDX (Figure $1, \mathrm{~B}$ and $\mathrm{C}$, lanes 5-8) cells revealed that only the furin was able to mediate complete rescue of PC activity in these cells. Similarly, using a specific IGF-1R antibody, we found that the processing of endogenous proIGF-1R was also blocked in HT-29/PDX and CT-26/PDX cells (Figure 1, D and E, lane 2), as shown by the accumulation of the precursor form $(\sim 200 \mathrm{kDa})$ and reduction of the mature form $(\sim 100 \mathrm{kDa})$ of IGF-1R. Expression of various PCs in HT-29/PDX and CT-26/PDX (Figure 1, D and E, lanes 3-6) revealed only furin restored the processing of proIGF-1R in these cells. These data demonstrate that the activity of the PCs in HT-29/PDX and CT-26/PDX cells is blocked.

PC blockade inbibits IGF-1-induced IGF-1R, IRS-1, and Akt phosphorylation. IGF-1R regulates multiple cellular functions affecting the metastatic phenotype of colon cancer cells. Suppression of IGF-1R expression or function by various strategies that affect its downstream effectors was previously reported to inhibit IGF-1-induced tumor growth and the formation of experimental liver metastases (19). Upon ligand binding, IGF-1R undergoes autophosphorylation on tyrosine residues of the $2 \beta$ subunits that leads to activation of the adaptor protein IRS-1. Activation of IRS- 1 further causes a phosphorylation cascade, which includes downstream kinases such as Akt $(13,19)$. Previous studies revealed that Akt activation promotes metastasis in a mouse model, and directly targeting its activity on tumor cells was suggested as a potential effective therapy $(20,21)$. To examine whether inhibition of IGF-1R processing affects IGF-1-mediated IGF-1R, IRS-1, and Akt phosphorylation, proteins were examined following 10 minutes' incubation of tumor cells with IGF-1. Analysis of cells kept in serum-free media condition prior to stimulation with IGF-1 revealed a detectable level of phosphorylated IGF-1R and IRS-1 (Figure 2, A and B), probably due to the effects of autocrine action of IGF-1 and IGF-2 on IGF-1R previously described in these cells $(22,23)$. In cells expressing $\alpha 1-P D X$, we observed a reduction of the basal level of phosphorylated proteins, and their phosphorylation was insensitive to IGF-1 (Figure 2, $A$ and $B)$. To determine whether inhibition of IGF-1R processing by $\alpha 1-P D X$ was capable of preventing signals transduced from IGF-1 through its receptor to Akt, tumor cells were incubated with IGF-1 and analyzed for Akt phosphorylation. While IGF-1 induced phosphorylation of this downstream kinase in control cells, expression of $\alpha 1-P D X$ reduced basal Akt phosphorylation and prevented IGF-1mediated Akt phosphorylation (Figure 2C).

Effect of siRNA-mediated PC silencing on IGF-1R processing and IGF-1induced Akt phosphorylation. RNA interference by siRNA is a process in which double-stranded RNA complexes can target specific genes 


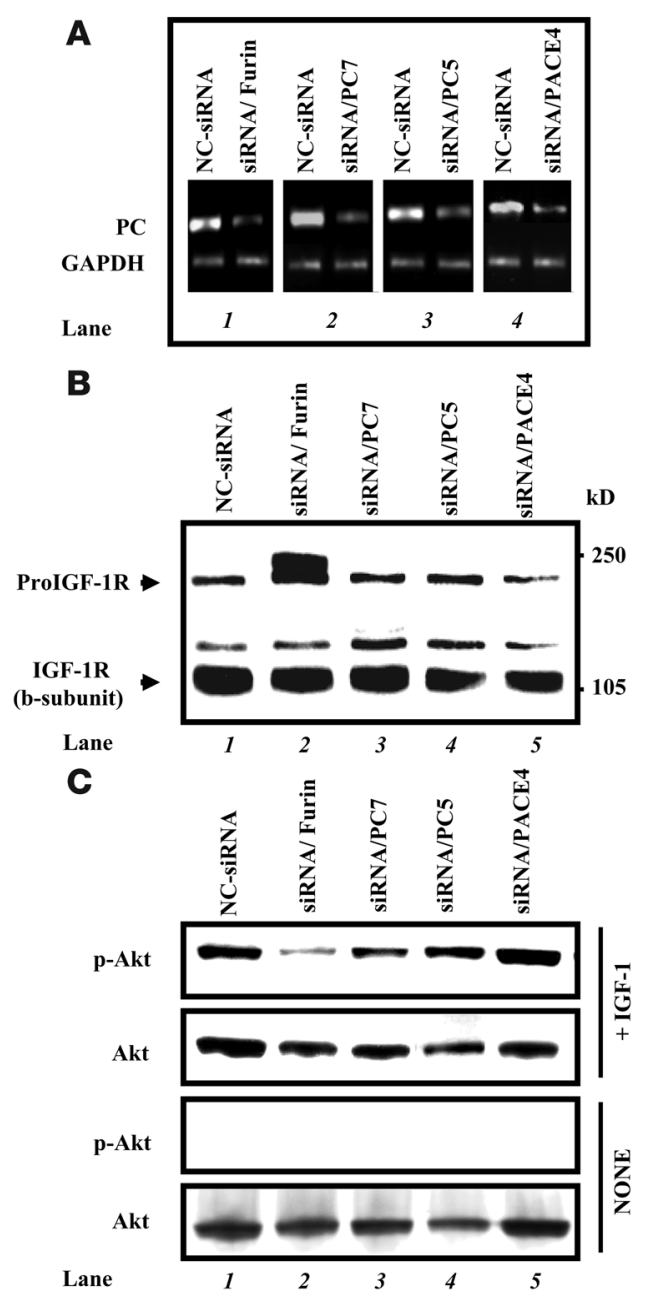

of homology for silencing. By introducing shorter synthetic duplex RNAs through transfection, siRNAs allow genes in cultured cells to be silenced (24). To confirm the endogenous processing of IGF-1R by the PCs and identify the convertase(s) involved in this processes, we used siRNAs to knock down the expression of furin, PC5, PACE4, or PC7 and examined IGF-1R processing and IGF-1-induced Akt phosphorylation in siRNA-transfected cells. To analyze the expression of every convertase, cells were first transfected with their corresponding siRNAs either individually $(100 \mathrm{nM})$ or as a pool of 4 siRNA (25 nM each). The 4 siRNAs used against furin, PC5, PACE4, or PC7 suppressed their expression with varying degrees of efficacy (data not shown). In Figure 3A, only the most effective siRNAs against furin, PC5, PACE4, or PC7 are represented. Of these, only siRNA against furin caused an accumulation of the unprocessed form of IGF-1R (Figure 3B, lane 2). Accordingly, following transfection of cells with siRNA against furin, PC5, PACE4, or PC7 and incubation with IGF-1, only siRNA against furin reduced IGF-1induced Akt phosphorylation (Figure 3C, lane 2).

Inhibition of PC activity alter E-selectin-dependent adhesion of tumor cells to endothelial cells. Adhesion of tumor cells on the vascular endothelium is a critical step of the metastatic invasion processes, particularly in the liver. Previously, various tumor cells including colon carcinoma cells were reported to release soluble factors capable of upregulating cell adhesion molecules expression on endothelial

\section{Figure 3}

siRNA-mediated PC silencing on IGF-1R processing and IGF-1induced Akt phosphorylation. (A) RT-PCR analysis was performed on RNA extracted from HT-29 cells transfected with siRNA against furin, PC5, PACE4, or PC7. Note the downregulation of indicated PCs by their corresponding siRNA. (B) Western blotting analysis of IGF-1R processing in HT-29 cells transfected with the indicated siRNAs revealed that only siRNA against furin inhibited the processing of IGF-1R. (C) Serum-starved cells transfected with the indicated siRNAs were stimulated for 10 minutes with $50 \mathrm{ng} / \mathrm{ml}$ IGF-1 and cell lysates were subjected to Western blotting using anti-phospho-Akt. Note that only silencing of furin by siRNA significantly affected Akt phosphorylation. The blots were stripped and re-probed with anti-Akt for data normalization. Results shown are representative of 3 experiments.

cells, including E-selectin, leading to tumor cells' adhesion on these cells $(25,26)$. To investigate whether inhibition of PC in colon cancer cells will affect these processes, murine hepatic sinusoidal endothelial cells were incubated with TNF- $\alpha$ or media derived from HT-29 or HT-29/PDX cells, and E-selection expression was analyzed by RT-PCR. As illustrated in Figure 4A, incubation of endothelial cells with TNF- $\alpha$ or media derived from control cells for 4 hours significantly induced E-selectin expression compared with media derived from tumor cells expressing $\alpha 1-P D X$. Using an adhesion assay, we found that the expression of E-selectin correlated with increased adhesion of HT-29 cells to endothelial cells. After 1 hour, the number of tumor cells that adhered to endothelial cells expressing E-selectin following activation with TNF- $\alpha$ or media derived from control tumor cells was up to 3.5-fold and 2.5-fold higher, respectively (Figure 4B). In contrast, media derived from HT-29/ PDX cells failed to significantly induce these processes (Figure 4B). An anti-E-selectin neutralizing antibody decreased the adhesion of tumor cells to the activated endothelial cells (Figure 4B), confirming that colon cancer cells adhere to activated endothelial cells in an E-selectin-dependent manner. These results indicate the importance of PCs in the generation of active soluble molecules responsible for the induction of E-selectin expression and subsequent tumor cell adhesion on endothelial cells.

Decreased cytokine levels in tumor cells expressing $\alpha 1-P D X$. The effect of PC inhibition on cytokine production by tumor cells was analyzed by RT-PCR and ELISA. Figure 4C shows that TNF- $\alpha$ and IL- $1 \alpha$ expressed by HT-29 cells was dramatically reduced by $\alpha 1$-PDX at the RNA level in these cells. Similarly, at the protein level, the amount of TNF- $\alpha$ and IL- $1 \alpha$ found in media of control cells collected 24 and 48 hours following incubation of cells in serum-free media was dramatically decreased in cells expressing $\alpha 1-P D X$, as determined by ELISA (Figure 4, D and E).

Inbibition of PCs attenuates induction of hepatic TNF- $\alpha$ expression in response to intrasplenic/portal inoculation of tumor cells. Previously, we have shown that only metastatic tumor cells entering the liver trigger a proinflammatory response that mediates the release of TNF- $\alpha$ and the upregulation of E-selectin $(6,7)$. To assess whether inhibition of PC activity in colon cancer cells affects their ability to induce TNF- $\alpha$ expression in vivo, the colon cancer cells CT-26, HT-29, CT-26/PDX, or HT-29/PDX were injected in the intrasplenic/portal route of mice. Livers were removed at indicated time periods and analyzed for TNF- $\alpha$ expression. After intrasplenic/ portal injection of control HT-29 cells (Figure 5A) or CT-26 cells (Figure 5B), there was a rapid increase in hepatic TNF- $\alpha$ mRNA expression. This increase was already detectable at 60 minutes. 
A

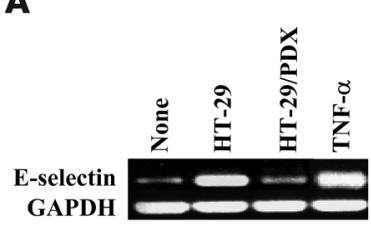

B
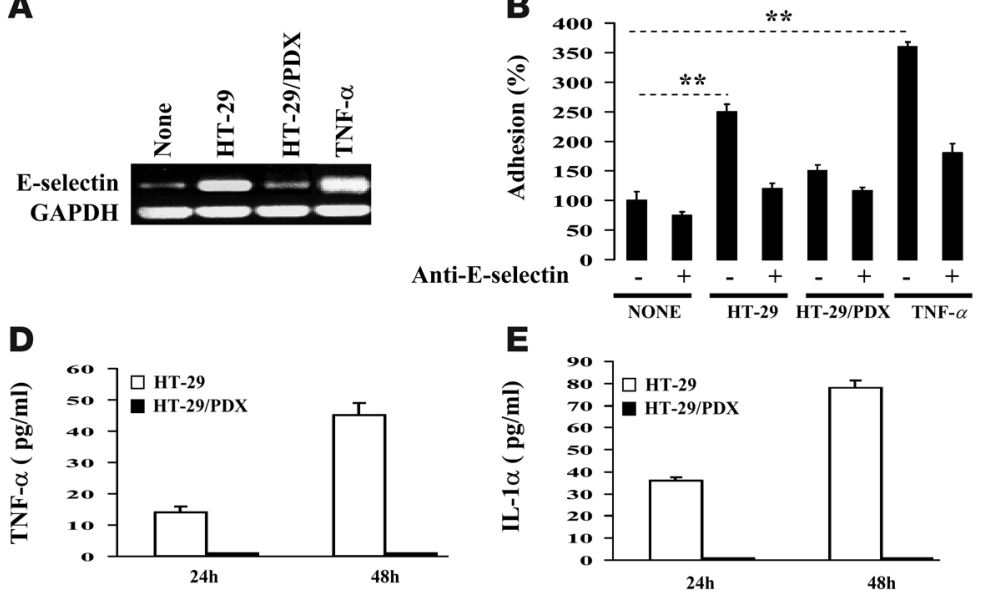

E

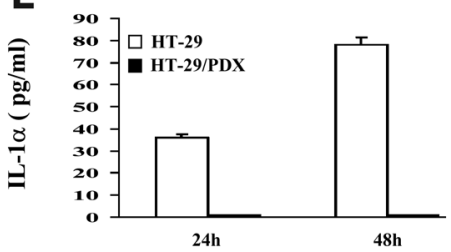

C

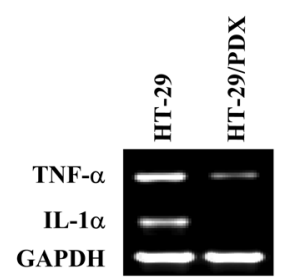

\section{Figure 4}

Inhibition of PC activity alter E-selectin-dependent adhesion of tumor cells to endothelial cells and cytokine production. (A) RT-PCR analysis was performed on RNA extracted from liver sinusoidal endothelial cells activated with TNF- $\alpha(10 \mathrm{ng} / \mathrm{ml}$, positive control) or media derived from HT-29 or HT-29/PDX cells using E-selectin and GAPDH-specific primers. Note that media derived from HT-29/PDX cells failed to significantly induce E-selectin expression compared with media derived from HT-29 cells or TNF- $\alpha$. (B) To test the effect of PC inhibition on tumor-endothelial cell adhesion, tumor cells were labeled with calcein and left to adhere to TNF- $\alpha(10 \mathrm{ng} / \mathrm{ml})$ or tumor cell-derived, conditioned media-activated endothelial layer in the presence or absence of an anti-E-selectin neutralizing antibody. The attached tumor cells were quantified by measuring the fluorescence emission using a fluorometer. Only TNF- $\alpha$ and media derived from control cells significantly induced HT-29 adhesion. (C) RT-PCR analysis was performed on RNA extracted from HT-29 and HT-29/PDX cells using TNF- $\alpha$, IL-1 $\alpha$, or GAPDH-specific primers. (D and E) Tumor cells were incubated at $37^{\circ} \mathrm{C}$ in serum-free media. After $24-48$ hours, media were collected and analyzed for the presence of IL-1 $\alpha$ and TNF- $\alpha$ using ELISA kit. Note the highly reduced expression and production of these cytokines in the presence of $\alpha 1$-PDX. Results shown are representative of 3 experiments. Data are mean \pm SEM $\left(n=3\right.$ per group). ${ }^{* *} P<0.001$.

Expression of TNF- $\alpha$ mRNA remained for up to 24 hours after tumor inoculation. Injection of CT-26/PDX or HT-29/PDX revealed a delayed and/or reduced induction of TNF- $\alpha$ mRNA expression (Figure 5, A and B). To analyze changes in hepatic TNF- $\alpha$ protein synthesis in response to tumor cells, Western blot and immunohistochemistry analyses were performed on liver extracts following 19-hour tumor cell injection. In livers obtained from mice injected with tumor cells expressing $\alpha 1-P D X$, weak expression (Figure 5C) and staining for TNF- $\alpha$ (Figure 5D) were observed compared with the increased TNF- $\alpha$ expression in livers obtained from control tumor cell-injected mice (Figure 5, C and D). No staining was expressed in saline-injected mice.

Inhibition of PCs attenuates induction of E-selectin expression in response to intrasplenic/portal inoculation of tumor cells. After injection of CT-26 or HT-29 cells, the increase in TNF- $\alpha$ expression was associated with an increase in E-selectin mRNA expression, which was measurable at 1-2 hours, reached maximal levels at 2-6 hours, and declined 8-12 hours after HT-29 (Figure 6A) and CT-26 (Figure 6B) cell inoculation. In contrast, in CT-26/PDX- or HT-29/PDXinjected mice, the expression levels of E-selectin were delayed and/ or lower and declined earlier compared with those observed in HT-29 or CT-26-injeced mice (Figure 6, A and B). Similarly, using an anti-E-selectin antibody, Western blot analysis (Figure 6C) and immunohistochemistry (Figure 6D) performed on livers obtained from tumor cell-injected mice revealed the inability of CT-26/PDX and HT-29/PDX cells to adequately induce hepatic E-selectin expression compared with controls (Figure 6, C and D).

PC blockade prevents tumor growth and experimental colorectal liver metastasis. To assess the role of the PCs on tumor growth and metastasis, we used the colon carcinoma cells CT-26 and HT-29. As previously observed with HT-29 cells (12), inhibition of the PCs in CT-26 cells reduced their ability to induce tumor growth in nude mice, confirming the importance of the PCs in the malignant phenotype of tumor cells (Figure 7). We then tested the effect of PC inhibition on the ability of HT-29 and CT-26 cells to colonize the liver. HT-29, CT-26, HT-29/PDX, or CT-26/PDX cells were injected in mice through the intrasplenic/portal route. At 2 weeks after injection of CT-26 and CT-26/PDX cells and 4 weeks after injection of HT-29 and HT-29/PDX cells, the livers were removed and the number of metastases was determined (Figure 8 and Table 1). In mice inoculated with tumor cells, the number of hepatic metastases was reduced by 50\% $(P<0.001)$ and $75 \%(P<0.001)$ in HT-29/PDX- and CT-26/ PDX-injected mice, respectively, relative to control animals (MannWhitney test; Table 1). To analyze the effect of PC inhibition on vessel formation in metastatic livers, tumor sections derived from mice inoculated with control cells or cells expressing $\alpha 1-P D X$ were stained with antibody against mouse CD-31. Results shown in Figure $8 \mathrm{~B}$ reveal decreased formation of vessels in HT-29/PDX-induced hepatic metastases compared with control HT-29 tumors.

$P C$ activity in colon cancer-derived hepatic metastases. To evaluate the PC activity in metastatic livers, tumor cells were injected in mice through the intrasplenic/portal route. After 2 or 4 weeks the livers were removed and lysed, and PC activity was analyzed by assessing the ability of liver-derived protein extracts to cleave the intramolecularly quenched fluorogenic peptide Q-h-VEGF-C that contains the PC cleavage site of VEGF-C (HSIIRR ${ }^{227} \mathrm{SL}$; ref. 27). In parallel, in these protein extracts the endogenous processing of IGF-1R was also examined. The results in Figure 9 revealed that the extent of cleavage of Q-h-VEGF-C by protein extracts of HT-29- or CT-26-derived metastatic livers was higher than that of HT-29/PDX- or CT-26/PDXderived metastases (Figure 9A), revealing the inhibition of the PC activity in HT-29/PDX- and CT-26/PDX-injected mouse livers. Mass 
A

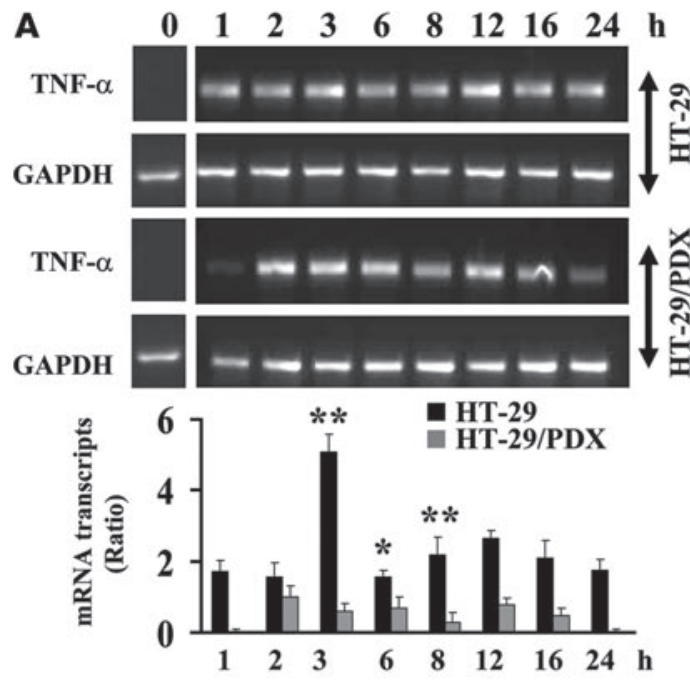

B
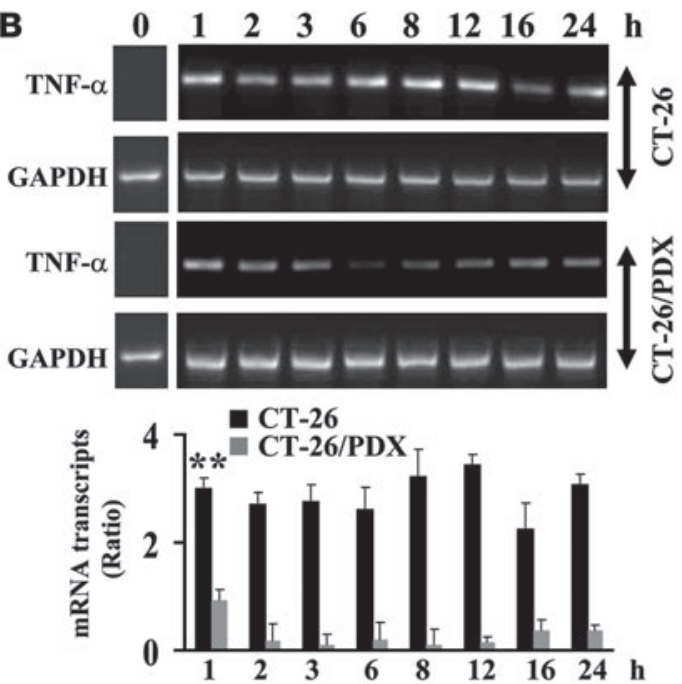

C

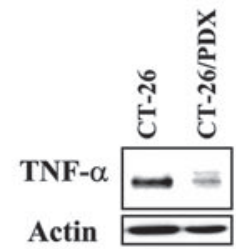

D
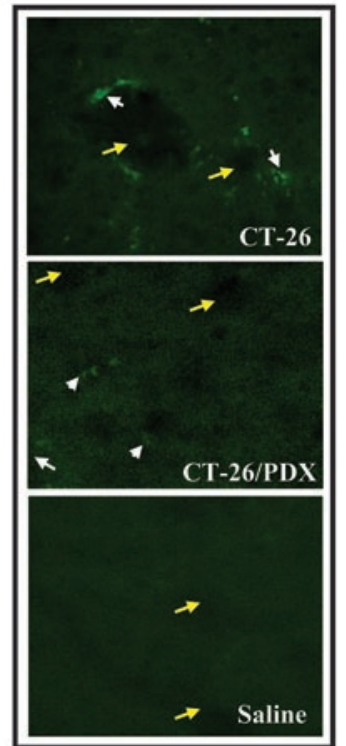

\section{Figure 5}

Induction of hepatic TNF- $\alpha$ mRNA by tumor cells. (A and $\mathbf{B}$ ) Mice were injected though the intrasplenic/portal route with $10^{6} \mathrm{HT}-29$, HT-26/ PDX (A), CT-26, or CT-26/PDX cells (B), and their livers were removed at the indicated times. Total RNA was extracted and analyzed by RT-PCR using specific primers for murine TNF- $\alpha$ or GAPDH. Results of laser densitometry are shown in the graph and are expressed as the ratio of TNF- $\alpha / G A P D H$ mRNA to that of control (liver of saline-injected mice at 1 hour), which was assigned a value of 1 . In Panel $\mathbf{A}$ and $\mathbf{B}$ the time zero data is from a different RT-PCR experiment done at the same time. (C) Western blotting analysis of TNF- $\alpha$ expression in response to tumor cells 19 hours after injection. (D) Immunohistochemistry analysis of liver sections derived from the animals 19 hours following injection of tumor cells. The sections were stained with an anti-murine TNF- $\alpha$ antibody (green stain, denoted by white arrows). Yellow arrows indicate the lumen of liver vessels. Note that cells expressing $\alpha 1$-PDX failed to induce adequately hepatic TNF- $\alpha$ expression compared with control cells. No significant staining was observed in uninjected or saline-injected mice. Original magnification, $\times 40$. Results shown are representative of 2 experiments. Values are mean \pm SEM ( $n=4$ per group). ${ }^{*} P<0.05,{ }^{* *} P<0.001$ versus respective $\alpha 1-P D X-$ expressing group. spectrometry and reverse-phase HPLC (Figure 9, B and C) confirmed that Q-h-VEGF-C was cleaved in vitro by liver extracts at the correct physiological HSIIRR ${ }^{227}$ SL site of VEGF-C (27). The reverse-phase HPLC chromatogram of the crude digest exhibited, in addition to a peak of undigested peptide (retention time $\left[R_{\mathrm{t}}\right], 30.1$ minutes; Figure 9B) identified by MALDI-ToF-MS as the Q-h-VEGF-C $(m / z=1,703$; Figure 9C), 2 additional peaks at $R_{\mathrm{t}}$ of 23.9 and 26.1 minutes (Figure 9C). These were identified by MALDI-ToF-MS as the highly fluorogenic N-terminal fragment Abz- ${ }^{220} \mathrm{Q}-\mathrm{VHSIIRR-OH}(\mathrm{m} / z=1,127)$ and the nonfluorescent C-terminal peptide SLP230-Y $\left(\mathrm{NO}_{2}\right)-\mathrm{A}-\mathrm{CONH}_{2}$ $(m / z=594$; Figure 9C). Similarly, immunoblotting analysis of protein extracts of CT-26-derived metastatic livers revealed that IGF-1R was almost completely processed, compared with those of CT-26/PDXderived metastases, where the processing of endogenous IGF-1R was blocked, as shown by the accumulation of the precursor form and reduction of the mature form of IGF-1R (Figure 9D).

\section{Discussion}

The complex interaction between tumor cells and the host microenvironment can significantly influence tumor progression and metastatic potential (5-10). A tumor cell that has entrenched at a distant site to form a metastatic lesion must be able to partici- pate and/or respond adequately to environmental stimuli, such as organ-specific adhesion molecules and growth factors (5-10). In liver, arrest of tumor cells in the hepatic circulation was previously reported to induce a variety of cytokines such as IL-1 and TNF- $\alpha$ that in turn upregulate the endothelial expression of various adhesion molecules, particularly E-selectin $(5-8,28-31)$. The latter was described as a crucial adhesion molecule in liver metastasis as revealed by the metastatic spread to the liver of various tumor cells that was inhibited by an anti-E-selectin antibody (29). Furthermore, liver metastasis of metastatic cells was inhibited by antibodies to sLewa ${ }^{\mathrm{a}}$, an E-selectin ligand used by tumor cells to adhere on vascular endothelial cells (30). Accordingly, we previously found that TNF- $\alpha$ mRNA expression was very rapidly augmented in liver within 6 hours of intrasplenic tumor injection (6). The expression of this cytokine was reported to be also enhanced around central and portal veins, presumed to be the entry sites of tumor cells to the liver (5). Thus, rapidly migrating tumor cells that induce the expression of TNF- $\alpha$ and probably other mediators enhance the expression of E-selectin, thereby increasing the interaction between tumor and endothelium, the first step of liver tumor colonization.

Recently, using various colon cancer cells, we found that intrasplenic administration of metastatic tumor cells was able to 

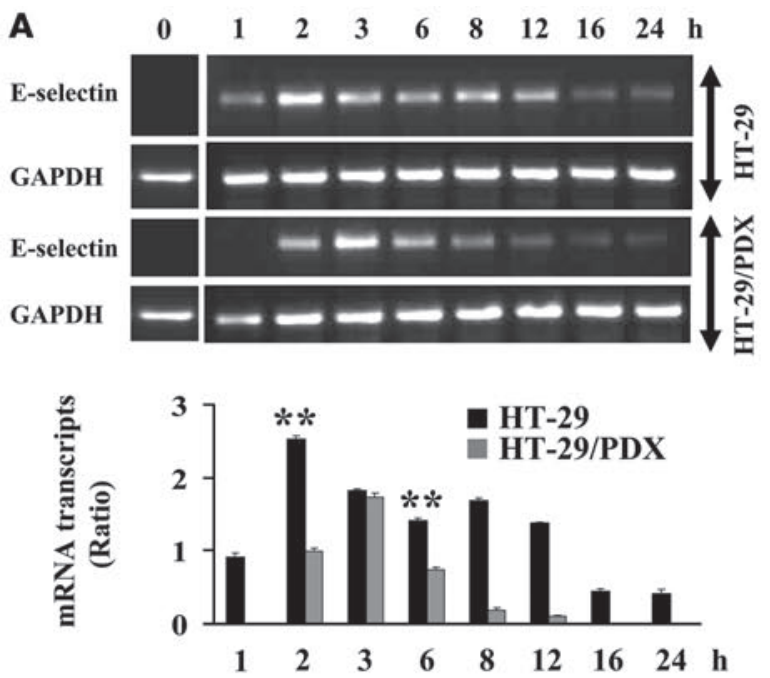

C

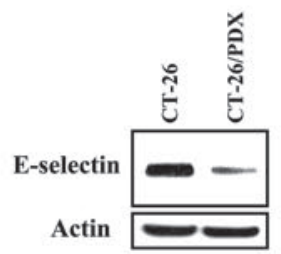

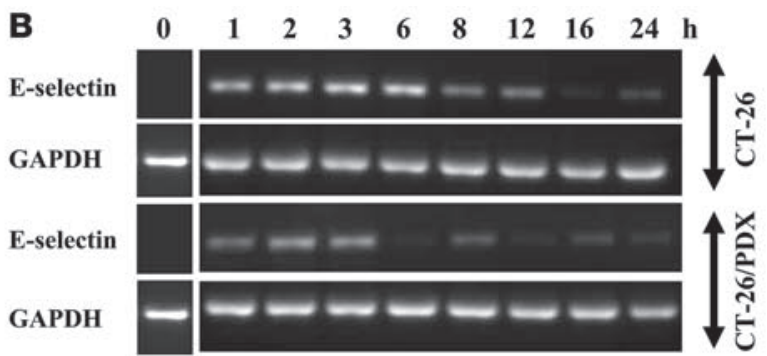

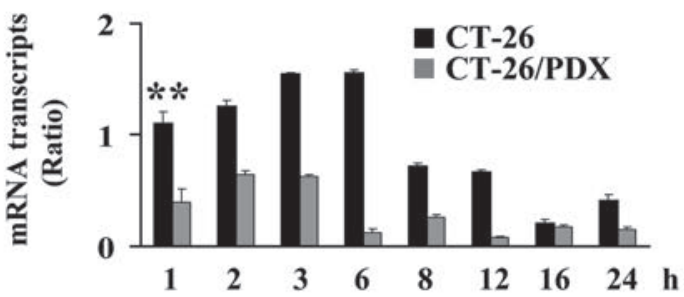

D

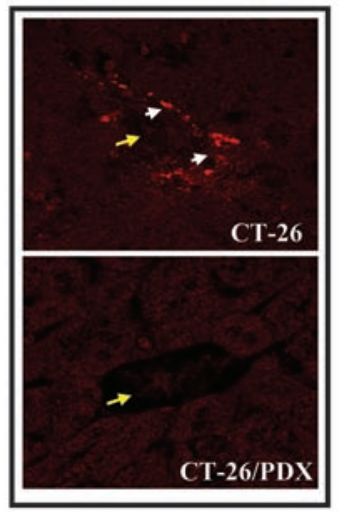

\section{Figure 6}

Hepatic E-selectin mRNA expression in response to tumor cells. After the injections of $10^{6}$ of CT-26, CT-26/PDX, HT-29, or HT-29/PDX cells, total RNA was extracted from mouse livers at different times and RT-PCR analysis was performed using E-selectin or GAPDH primers. Results of laser densitometry are shown in the bar graph and are expressed as the ratio of E-selectin/GAPDH mRNA to that of control (liver of salineinjected mice at 1 hour), which was assigned a value of 1 . In Panel $\mathbf{A}$ and $\mathbf{B}$ the time zero data is from a different RT-PCR experiment done at the same time. (C) Western blotting analysis of E-selectin expression in response to tumor cells 19 hours after injection. (D) Immunohistochemistry analysis of liver sections derived from the animals 19 hours following injection of tumor cells. Sections were stained with an anti-E-selectin antibody (red stain, denoted by white arrows). Note that cells expressing $\alpha 1$-PDX failed to adequately induce hepatic E-selectin expression compared with control cells. Original magnification, $\times 40$. Results shown are representative of 2 experiments. Values are mean \pm SEM $(n=4$ per group). ${ }^{\star} P<0.05 ;{ }^{* \star} P<0.001$.

induce TNF- $\alpha$ production by Kupffer cells (7). Colocalization studies revealed that these cells constitute the major source of TNF- $\alpha$ in tumor cell-inoculated livers (7). The factors that regulate this host inflammatory response to tumor cells are not presently known. However, the previously observed proximity of the TNF- $\alpha$-positive Kupffer cells to tumor-infiltrated vessels (7) suggests that tumor cells may produce soluble mediators that can directly activate endothelial cells or indirectly through activated Kupffer cells that release cytokines to express E-selectin. This is in agreement with previous reports based on in vitro studies that showed the ability of medium conditioned by metastatic colon cancer cells to trigger TNF- $\alpha$ production by macrophages (7), suggesting that the ability of these tumors to induce a host inflammatory response in vivo is due, at least in part, to tumor-derived soluble factors. Similarly, using C-raf antisense oligonucleotides, we were previously able to abrogate in vitro and in vivo the abil- ity of tumor cells to mediate cytokine-dependent induction of E-selectin expression and liver metastasis (8), suggesting that E-selectin expression on endothelial cells is induced by tumor cell-derived molecules that activate the Ras/Raf/mitogen-activated protein kinase pathway (8). Indeed, various colon carcinoma cells were reported to release soluble factors capable of upregulating cell adhesion molecules expression on endothelial cells, including E-selectin leading to tumor cell adhesion on these cells. These include cytokines such as IL-1, IL- 6 , and TNF- $\alpha$. The latter were found to be produced by tumor cells metastasizing to the liver, such as breast cancer and colon carcinoma $(25,26$, 31-33). Accordingly, previous studies revealed that the levels of these cytokines were significantly higher in colon carcinoma cell supernatants as compared to normal colon tissue (33). In addition to cytokines, other mediators produced by tumor cells were also found to be involved in the induction of E-selectin expression 

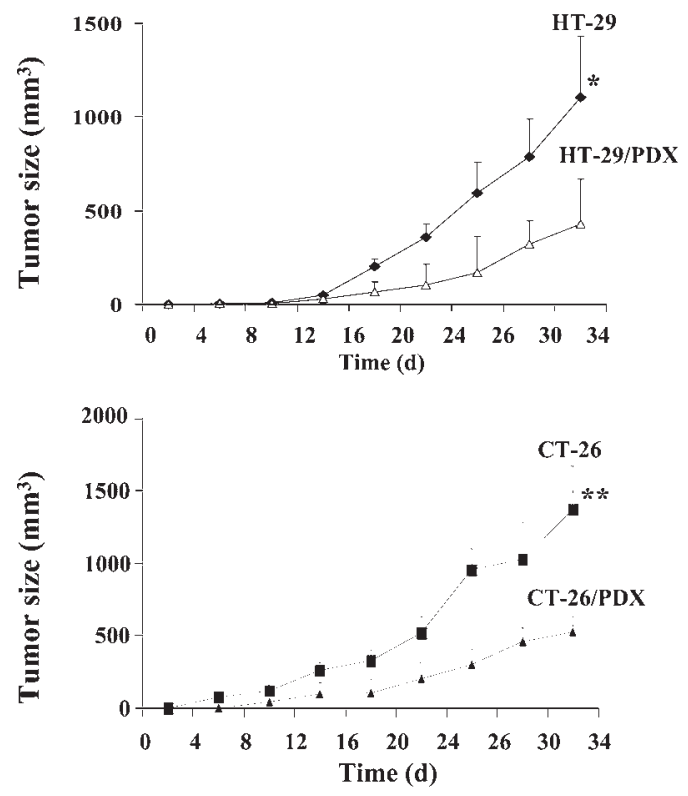

such as VEGF (34), IGF-1 (35), PDGF (36), and endothelin (37). Many of these proteins directly or indirectly require PC activity to exhibit their secretion or full biological activity (15). Thereby inhibition of their maturation or expression may affect their ability to induce E-selectin expression and adhesion on endothelial cells. Indeed, we found that suppression of PC activity following the expression of the general PC inhibitor $\alpha 1-\mathrm{PDX}$ in the metastatic colon carcinoma cells attenuated significantly the ability of their conditioned media to induce E-selectin expression and colon cancer cell adhesion on endothelial cells (Figure 4). These data suggest the importance of PCs in the generation of active soluble molecules responsible for the induction of E-selectin expression and subsequent tumor cell adhesion on endothelial cells. Indeed, analysis of TNF- $\alpha$ and IL- $1 \alpha$ secretion in conditioned media derived from tumor cells expressing $\alpha 1-\mathrm{PDX}$ revealed their highly reduced levels (Figure 4D). Likewise, inoculation of CT-26/PDX or HT-29/PDX into hepatic circulation failed to induce significantly hepatic TNF- $\alpha$ (Figure 5) and E-selectin expression (Figure 6) as well as metastases formation in liver (Table 1). These results indicate that the PCs contribute to metastasis by enhancing the levels of active molecules involved in the first step of liver colonization by tumor cells as revealed by the low PC activity in HT-29/ PDX- and CT-26/PDX-derived hepatic metastases (Figure 9).

Following their adhesion on liver endothelial cells, the survival and growth of metastatic tumor cells in the liver required the availability of various autocrine/paracrine growth-promoting factors and their receptors. Of these molecules, IGF-1 and its receptor IGF-1R

\section{Figure 8}

$P C$ inhibition prevents experimental liver metastasis and tumor vessel formation. (A) Experimental liver metastases were generated by intrasplenic/portal injection of tumor cells, as described previously (6-8). HT-29, HT-29/PDX, CT-26, or CT-26/PDX cells $\left(1 \times 10^{6}\right)$ were injected into mice through intrasplenic/portal route, and liver metastases were enumerated 2 weeks after injection of CT-26 or CT-26/PDX cells and 4 weeks after injection of HT-29 or HT-29/PDX cells. (B) Developed liver tumors derived from HT-29- and HT-29/PDX-inoculated mice were analyzed for angiogenesis using an anti-mouse CD31 antibody. Original magnification, $\times 200$.

\section{Figure 7}

In vivo tumorigenicity assay. HT-29, HT-29/PDX, CT-26, or CT-26/PDX cells $\left(1 \times 10^{6}\right)$ were injected subcutaneously into 4-week-old female nude mice. The animals were monitored for tumor formation every 3 days. Results are representative of 4 experiments. Values are mean \pm SEM ( $n=6$ per group). ${ }^{\star} P<0.05 ;{ }^{\star \star} P<0.01$.

were reported to affect tumor metastasis through mediation of antiapoptotic and proangiogenic activity as well the regulation of tumor cell proliferation (9-13). The liver is the major endocrine source of IGF-1 production. Under normal conditions, activation of IGF-1R by its ligand IGF-1 results in its phosphorylation, followed by the phosphorylation of several substrates including IRS-1 (12, $13,19)$. In turn, this triggers other signal transduction pathways including the Akt-dependent pathway implicated in cell survival, angiogenesis, and metastasis (13, 20, 21). Previously, IGF-1R blockade by various strategies, including the use of antisense oligonucleotides $(38,39)$, IGF-1 peptide analogs (40), triple-helix forming oligodeoxynucleotides (41), single chain antibodies (42), and siRNA (43), suggest the importance of fully functional receptor in tumorigenesis and metastasis. Thereby it is possible that the IGF-1R neutralizing strategy can enhance the effects of chemotherapy (44) and radiation therapy (45) by potentiating the apoptosis induced by these treatments. In the present study, we found that inhibition of PC activity in colon carcinoma cells by the general PC inhibitor $\alpha 1-P D X$ revealed that these cells were unable to convert IGF-1R into its mature form (Figure 1, D and E).

To date, although several PC crystal structures are available, it is still not possible to predict which PC cleaves which substrate. The in vitro cleavage assays are also of restricted use, since they tend to generate false positives due to the absence of the cellular context
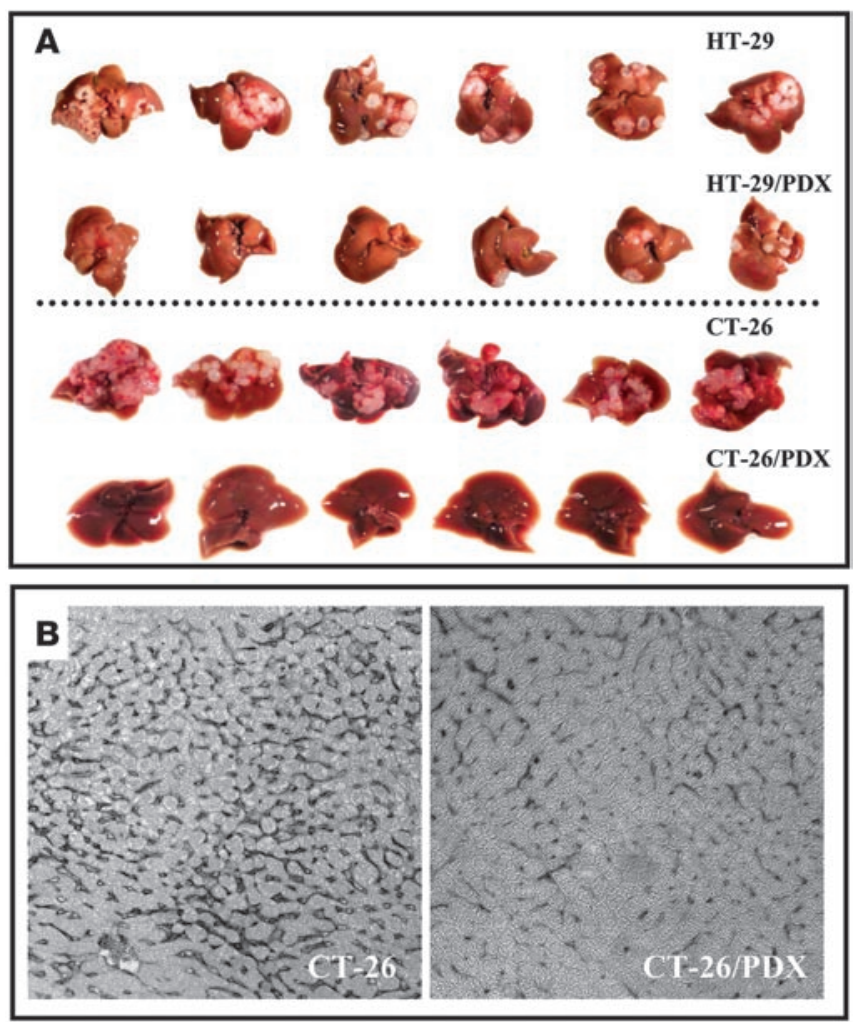
Table 1

Metastasis incidence and prevalence and liver weight

\begin{tabular}{lccc} 
Cell line & $\begin{array}{c}\text { Metastasis } \\
\text { incidence }\end{array}$ & $\begin{array}{c}\text { No. metastases } \\
\text { per liver (range) }\end{array}$ & $\begin{array}{c}\text { Liver weight } \\
(\mathbf{g})^{\mathrm{A}}\end{array}$ \\
HT-29 & $100 \%$ & $22-250$ & $3.5 \pm 1.4$ \\
HT-29/PDX & $50 \%$ & $6-15$ & $1.4 \pm 0.15$ \\
CT-26 & $100 \%$ & $80-450$ & $4.1 \pm 1.2$ \\
CT-26/PDX & $25 \%$ & $0-30$ & $1.5 \pm 0.4$ \\
\hline
\end{tabular}

Shown are results of 1 representative experiment of 3 performed $(n=6$ per group, Mann-Whitney test). ${ }^{\mathrm{A}} \mathrm{Data}$ are mean $\pm \mathrm{SD}$.

and nonphysiological stoichiometries. Recently only the knockdown of a specific PC using gene-silencing methods revealed the existence of specific substrate(s) for specific PC(s) (46-49). Previously, overexpression of various PCs in the PC activity-deficient cells LoVo revealed that only furin mediates almost complete processing of IGF-1R (12). Similarly, overexpression of furin, PC5, PACE4, or PC7 in tumor cells expressing $\alpha 1-\mathrm{PDX}$ and the use of siRNA against these PCs revealed that furin was the IGF-1R convertase (Figure 3B). The unprocessed receptor failed to mediate IGF-1 intracellular signaling, as revealed by reduced IGF-1R, IRS-1, and Akt phosphorylation (Figure 2 and Figure 3C). The ability of $\alpha 1-P D X$ and siRNA against furin to abrogate IGF-1-mediated Akt pathway activation seems to be responsible for the reported finding of the failure of IGF-1 to stimulate $\left[{ }^{3} \mathrm{H}\right]$ thymidine incorporation and mediate cell protection from apoptosis in HT-29/PDX cells (12). Additionally, $\alpha 1-\mathrm{PDX}$ inhibits also the processing of proIGF-1 (50) and proIGF-2 (51), known to be synthesized and secreted by these cells $(22,23)$. Since overexpression of $\alpha 1-P D X$ in tumor cells inhibited the processing of IGF-1R and its furinprocessed ligands, IGF-1 and IGF-2, it is liable to abrogate their autocrine/paracrine antiapoptotic and proliferative actions, 2 processes required for tumor and metastasis progression. Previously, immunohistochemical analysis of CD31 antigen expression revealed reduced vascularization of subcutaneous HT-29/PDX tumors (12). Similar analysis performed on HT-29/PDX-derived liver metastases revealed also their low vascularization (Figure 8B). Accordingly, using an in vitro angiogenesis assay we found that incubation of endothelial cells with synthetic $\alpha 1$-PDX block tube formation (data not shown). These observations suggest the importance of the PCs in tumor vessel formation through activation of various PC substrates including IGF-1R and VEGF-C. Indeed, the processing of the latter by the PCs was previously reported to be required for tumor angiogenesis (27). In the same way, hypoxiainducible factor- 1 , an inducer of various genes involved in angiogenesis is positively regulated by IGF systems (52). Thus inactivation of IGF-1R by $\alpha 1-P D X$ may also inhibit tumor growth and vascularization via its abrogation. Indeed, analysis of metastatic livers obtained after tumor cell injection in the hepatic circulation revealed significantly reduced activity of PCs in tumor cells expressing $\alpha 1-\mathrm{PDX}$ derived from metastatic livers, as assessed by the processing of the synthetic fluorogenic peptide mimicking the cleavage site of PC found in proVEGF-C (Figure 9). In these livers IGF-1R processing was found to be inhibited (Figure 9). Accordingly, previous analysis of tumors and lung metastases induced in HT-29/PDX-injected immunosuppressed newborn rats revealed that these tumors still express $\alpha 1-P D X$ that coincides with their inability to cleave the PC substrate integrin av subunits (53).
Recently, in addition to its role as a growth-promoting factor that enhances the growth of metastatic colon cancer cells in the liver, IGF-1 was reported to regulate the tumor-induced inflammatory response by suppressing the production of the secretory leukocyte protease inhibitor, an antiinflammatory modulator (54). This was identified as an inhibitor of liver metastasis due to its ability to suppress the tumor cell-induced host proinflammatory response during the early stages of liver colonization. Inhibition of its production by IGF-1 was found to allow TNF- $\alpha$ production that initiates the molecular cascade required for metastases formation (54). In our model the inhibition of IGF-1R processing in tumor cells may also affect this new function of IGF-1, leading to the reduced ability of tumor cells expressing $\alpha 1$-PDX to induce TNF- $\alpha$ and E-selectin in vivo. However, further investigations are required to elucidate the role of the PCs in these processes. The present study demonstrates the importance of PCs in early and late liver colonization by metastatic colon cancer cells and suggests the potential use of PC inhibitors as new therapeutic agents for liver colorectal metastasis prevention. In certain situations specific inhibition of a single PC may be sufficient and more appropriate, as previously reported for furin, the specific inhibition of which was revealed to abolish the malignant phenotype of various malignancies (55). Evidently, more understanding of the molecular mechanisms of the PC inhibitors by using various in vitro and in vivo models is required before testing their efficacy in human cancers.

\section{Methods}

Cell transfection and culture. The characteristics and the origin of the control and stably $\alpha 1-$ PDX-transfected HT-29 (HT-29/PDX) human colon adenocarcinoma cell lines were described previously (12). The CT-26 murine colon adenocarcinoma cells were stably transfected with the empty PIRES2-EGFP vector or with the same vector containing the full-length $\alpha 1$ PDX cDNA (CT-26/PDX). As described previously for the generation of a single mixture of HT-29 cells expressing $\alpha 1$-PDX cDNA (HT-29/PDX) (12), a mixture of G418-CT-26/PDX-resistant cells were selected and screened for $\alpha 1$-PDX expression by Western blotting. To generate single-mixture cells expressing the $\alpha 1-\mathrm{PDX}$ inhibitor, the CT-26/PDX cells were cultured in the presence of $1 \mu \mathrm{g} / \mathrm{ml}$ Psendomonas exotoxin A (12). This toxin mediates cells death only after its cleavage by the PCs (56). Cells were grown in Dulbecco modified Eagle medium supplemented with 10\% FCS, $100 \mathrm{U} / \mathrm{ml}$ penicillin, $100 \mathrm{mg} / \mathrm{ml}$ streptomycin, and $200 \mu \mathrm{g} / \mathrm{ml} \mathrm{G} 418$. In some experiments, HT-29 and CT-26 cells and the same cells expressing $\alpha 1-P D X$ were transiently transfected with the pIRES2-EGFP-V5 empty vector or containing PDGF-A cDNA and/or vector containing full-length furin, PACE4, PC5, or PC7 cDNA to assess the activity of the PCs in these cells. All the transfections were carried out using Lipofectamine reagent (Invitrogen) as recommended by the manufacturer.

RNA interference. Tumor cells were plated in a 6-well plate. When the cells were $60 \%$ confluent, medium was replaced with serum-free media and cells were transfected with siRNA. Predesigned siRNAs were obtained from Dharmacon to interfere with the expression of furin, PCAC4, PC5, or PC7 according to the manufacturer's instructions. Briefly, Lipofectamine $(10 \mu \mathrm{l})$ and siRNAs were transfected either individually $(100 \mathrm{nM})$ or as a pool of 4 siRNAs (25 nM each). After 24-48 hours, cells were subjected to RT-PCR or Western blot analysis. In some experiments, following siRNA transfection, cells were stimulated for 10 minutes with $50 \mathrm{ng} / \mathrm{ml} \mathrm{IGF-1} \mathrm{and} \mathrm{cell}$ lysates were subjected to Western blotting. The sense and antisense strands of the most effective PCs siRNAs tested were as follows: furin siRNA sense, CAGCUGCGCUCUGGCUUUAUU (sense) and UAAAGCCAGAGCGCAGCUGUU (antisense); PACE4, CGUCAGCGCUGUACCGAUGUU 

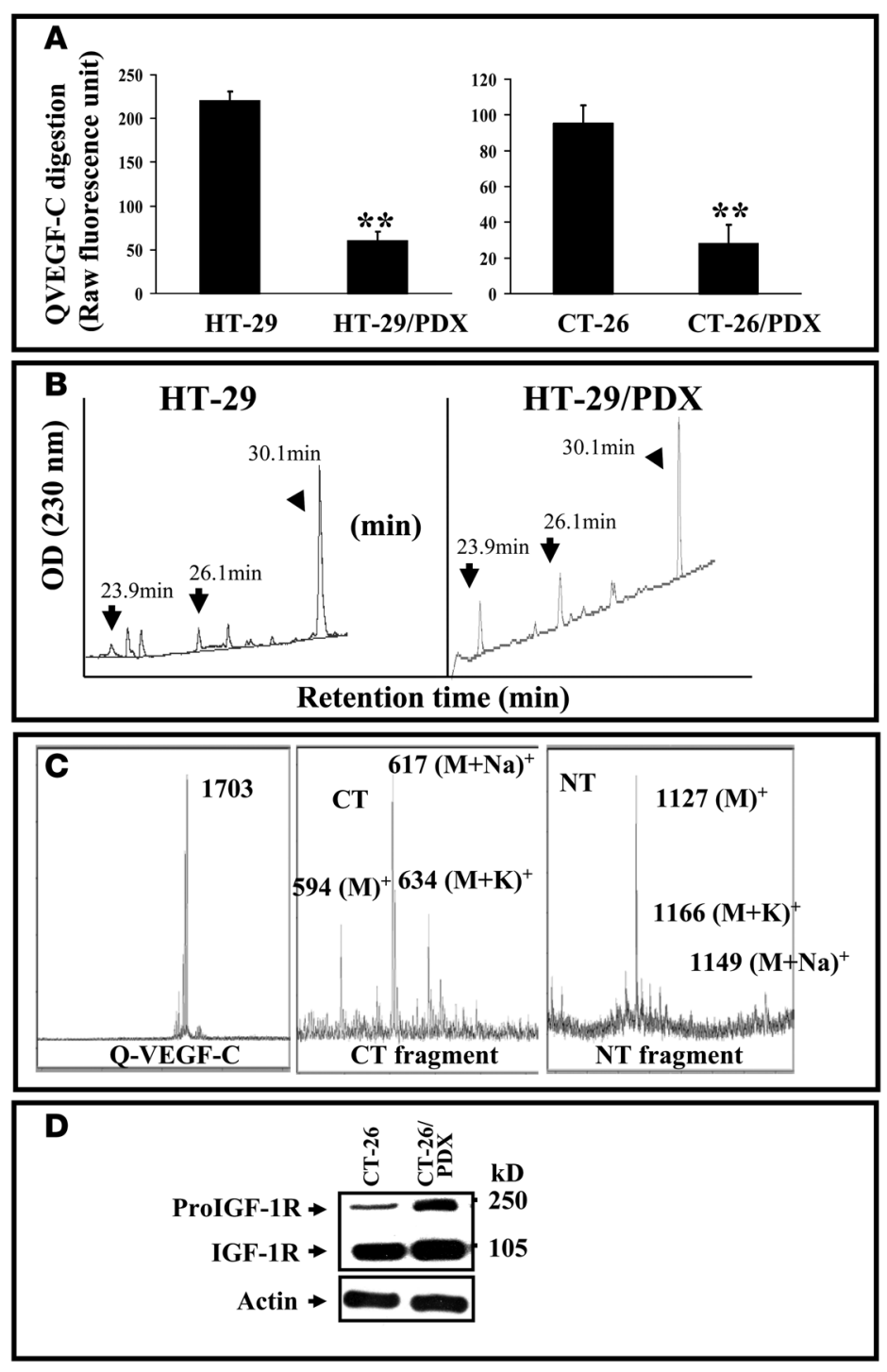

\section{Figure 9}

PC activity in tumor cell-derived liver metastases. (A) Indicated tumor cells were injected in mice through the intrasplenic/portal route. After 2 or 4 weeks, livers were removed and lysed in phosphate-buffered saline. Protein extracts were incubated with the intramolecularly quenched fluorogenic peptide Q-h-VEGF-C containing the PC processing site of VEGF-C, and the digestion of the QVEGF-C was evaluated as raw fluorescence units. (B) Aliquots of the enzymatic reaction reversephase HPLC chromatogram of the crude digest following incubation at $37^{\circ} \mathrm{C}$ of $20 \mu \mathrm{g}$ QVEGF-C with liver protein extract. The elution of the peaks was monitored online by UV absorbance at $214 \mathrm{~nm}$ as well as by fluorescence detectors. (C) MALDI-ToF mass spectra of the crude digests following incubation of QVEGF-C with liver protein extract. The peak at $m / z 1,703$ is attributed to QVEGF-C. The peaks at $m / z 1,127$ and 594 were attributed to the highly fluorescent N-terminal [NT; Abz-Q-VHSIIRR-OH] and the nonfluorescent C-terminal [CT; SLP $\left(\mathrm{NO}_{2}\right)$-A$\mathrm{CONH}_{2}$ ] fragments, respectively. (D) Immunoblotting analysis of IGF-1R processing in protein extracts derived from indicated tumor cell-derived metastases revealed the inhibition of IGF-1R processing in CT-26/PDX-derived metastases. Results are representative of 3 experiments. Values are mean \pm SEM ( $n=3$ per group). ${ }^{\star \star} P<0.001$.

lulose membranes. The primary antibodies used were anti-IGF-1R (Santa Cruz Biotechnology Inc.), anti-TNF- $\alpha$ (Abcam), antiE-selectin (Abcam), and anti-V5 (Invitrogen). Primary antibodies were revealed by horseradish peroxidase-conjugated secondary antibodies (Amersham Pharmacia Biotech) and enhanced chemiluminescence (ECL+Plus; Amersham Pharmacia Biotech) according to the manufacturer's instructions.

IGF-1R, IRS-1, and Akt tyrosine phosphorylation. Colon cancer cells were maintained in serum-free media condition for $24-48 \mathrm{~h}$ and incubated with or without IGF-1 $(50 \mathrm{ng} / \mathrm{ml})$ for 2 minutes at $37^{\circ} \mathrm{C}$. After this period, cells were lysed with lysis buffer (50 mM HEPES, $150 \mathrm{mM}$ $\mathrm{NaCl}, 1 \%$ Triton X-100, $2 \mathrm{mM}$ vanadate, $100 \mathrm{mM} \mathrm{NaF}$, and $0.40 \mathrm{mg} / \mathrm{ml}$ phenylmethylsulfonyl fluoride). Equal amounts of proteins were immunoprecipitated overnight with anti-IGF-1R or IRS-1 polyclonal antibody (Santa Cruz Biotechnology Inc.), and the whole pellets were analyzed by Western blotting using anti-phosphotyrosine (SigmaAldrich) as previously described (12). In other experiments, cell lysates

(sense) and CAUCGGUACAGCGCUGACGUU (antisense); PC5, GAUACUCCCUCUCAGCUAAUU (sense) and UUAGCUGAGAGGGAGUAUCUU (antisense); PC7, CUACGUCAGUCCCGUGUUAUU (sense) and UAACACGGGACUGACGUAGUU (antisense). Negative control siRNA (D-00181001-20) obtained from Dharmacon was used for nonspecific interference.

RT-PCR analysis. Total RNA was extracted using Trizol reagent (Invitrogen) according to the manufacturer's instructions and reverse transcribed in a $20-\mu \mathrm{l}$ reaction mixture containing $50 \mathrm{mM}$ Tris- $\mathrm{HCl}$ ( $\mathrm{pH} 8.3$ ), $30 \mathrm{mM} \mathrm{KCl}$, $8 \mathrm{mM} \mathrm{MgCl}_{2}, 1 \mathrm{mM}$ dNTPs, and $0.2 \mathrm{U}$ Superscript reverse transcriptase (Invitrogen). The mixture was sequentially incubated for 10 minutes at $25^{\circ} \mathrm{C}, 60$ minutes at $37^{\circ} \mathrm{C}$, and 5 minutes at $95^{\circ} \mathrm{C}$. cDNAs were amplified by PCR using specific primers for the indicated genes, as described previously $(6,27)$. The PCRs were performed in a buffer supplied by the manufacturer in which the cDNA sample, $5 \mu \mathrm{M}$ each primer, $200 \mu \mathrm{M}$ dNTPs, and $0.2 \mathrm{U}$ Taq polymerase were added. The conditions for the reaction were as follows: 30 seconds at $94^{\circ} \mathrm{C}, 30$ seconds at $56^{\circ} \mathrm{C}$, and 30 seconds at $72^{\circ} \mathrm{C}$ for 25 cycles. The amplified PCR products were analyzed on a $1.5 \%$ agarose gel.

Immunoblotting. After transfection, conditioned media were collected and cells were lysed in PBS containing 2\% NP-40. Cell lysates were subjected to SDS-PAGE on $8 \%-10 \%$ gels, and proteins were blotted onto nitrocelwere analyzed by Western blotting for tyrosine phosphorylation and Akt phosphorylation using anti-phosphotyrosine and anti-phospho-Akt, respectively (Cell Signaling). The blots were stripped and reprobed with anti-actin (Sigma-Aldrich) or anti-Akt (Cell Signaling) for data normalization.

Measurement of TNF- $\alpha$ and IL-1 $\alpha$ production by tumor cells. Tumor cells were plated in 6-well plates and incubated at $37^{\circ} \mathrm{C}$ in serum-free media. After $24-48$ hours, media were collected and analyzed for the presence of IL- $1 \alpha$ and TNF- $\alpha$ using the cytokine ELISA kit according to the manufacturer's instructions (R\&D Systems). Cytokine concentrations were calculated from a standard curve.

Tumor-endothelial cell adhesion assay. Liver sinusoidal endothelial cells were obtained from normal C57BL/6 mice by liver perfusion as we described previously (8). To test the effect of PC inhibition on tumor-endothelial cell adhesion, tumor cells were labeled with calcein and left to adhere to TNF- $\alpha(10 \mathrm{ng} / \mathrm{ml})$ or tumor cell-derived, conditioned media-activated endothelial layer for 120 minutes at $37^{\circ} \mathrm{C}$ in the presence or absence of an anti-E-selectin neutralizing antibody during the last 60 minutes. The endothelial layer was washed twice with phosphate-buffered saline, and the attached cells were quantified by measuring the fluorescence emission using a fluorometer. 
Tumorigenicity assay. All experiments performed in this study were approved by the Clinical Research Institute of Montreal Animal Ethics Committee. Female 4- to 6-week-old nu/nu mice from Charles River Laboratories, housed in a pathogen-free facility, were used for all of the experiments. To assess the effect of PC inhibition on tumor growth, $1 \times 10^{6}$ HT-29, CT-26, HT-29/PDX, or CT-26/PDX cells were injected subcutaneously into nude mice, tumor formation was monitored every 3 days, and mice were sacrificed 30-34 days after injection. Tumor volume was calculated as previously described (12).

Intrasplenic/portal injections. 4- to 6-week-old female nu/nu mice were anesthetized by methoxyflurane and the spleens were exposed through a small abdominal incision; $1 \times 10^{6}$ tumor cells in $0.1 \mathrm{ml}$ saline were inoculated as previously described (6-8). The livers were removed at various time periods, snap-frozen in liquid $\mathrm{N}_{2}$, and stored until analysis by RT-PCR.

Liver metastasis assay. Experimental liver metastases were generated by intrasplenic/portal injection of $1 \times 10^{6}$ of HT-29, CT-26, HT-29/PDX, or CT-26/PDX cells (6-8). CT-26 cells were very aggressive cells following their intrasplenic/portal route inoculation; the livers were completely full of metastases within 2 weeks. Similar results were obtained with HT-29 cells only 4-5 weeks following their inoculation. Because of the high aggressiveness of the CT-26 colon cancer cells, the CT-26 and CT-26/PDX-injected nude mice were killed 2 weeks after the injection, whereas HT-29- and HT-29/PDX-injected nude mice were killed 4 weeks later. Livers were removed and the metastases were enumerated, without prior fixation (8).

Immunohistochemical analyses. Following tumor injection, $20-\mu \mathrm{m}$ paraformaldehyde-fixed liver sections were incubated with antibodies to murine TNF- $\alpha$ (Abcam) and E-selectin (R\&D Systems) as described previously with modification (6). Briefly, blocking serum was applied to the tissue for 30 minutes to reduce nonspecific binding, and then the tissue sections were incubated with the primary antibody for 2 hours. The sections were washed and incubated for 1 hour at room temperature either with a Texas Red-conjugated secondary antibody (Abcam) for detection of E-selectin or with a FITC-conjugated secondary antibody (Abcam) for detection of factor TNF- $\alpha$. After washing, the sections were mounted in $10 \%$ glycerol and examined using a Zeiss Axiophot epifluorescence microscope. In parallel, angiogenesis was quantitated in tumor sections by counting the number of CD31-positive vascular vessels using an anti-CD31 as primary antibody and a horseradish peroxidase-conjugated secondary antibody following incubation of sections in citrate buffer solution.

Peptide synthesis and in vitro digestions. To analyze the PC enzymatic activity in tumor cell-derived metastases 2-4 weeks after tumor cell intrasplenic injection, metastatic livers were removed and lysed in phosphate-buffered saline. Equal amount of liver protein were incubated with $10 \mathrm{mM}$ intramolecularly quenched fluorogenic peptide Q-h-VEGF-C $\left[\mathrm{Abz}^{-220} \mathrm{Q}-\right.$ VHSIIRRSLP ${ }^{230}-\mathrm{Y}_{(}\left(\mathrm{NO}_{2}\right)-\mathrm{A}-\mathrm{CONH}_{2}$ ] containing the PC processing site of VEGF-C (27). Aliquots of the enzymatic reaction were collected, and the processing of the VEGF-C-derived peptide was determined as previously described using HPLC and mass spectral analysis of isolated peaks (27).

Statistics. Unless otherwise indicated, results were compared using Student's $t$ test. A $P$ value less than 0.05 was considered significant.

\section{Acknowledgments}

This work was supported by grants from la Ligue Nationale Contre le Cancer and Avenir Award (Paris, France) to A.-M. Khatib and CIHR grant no. MGP-44363 and Canada Chair to N.G. Seidah. The authors are grateful to Nathalie Ba for her technical help.

Received for publication March 6, 2007, and accepted in revised form October 17, 2007.

Address correspondence to: A.-M. Khatib, Laboratoire de Pharmacologie Expérimentale et Clinique, INSERM U716/Equipe AVENIR, Institut de Génétique Moléculaire, 27 rue Juliette Dodu, 75010 Paris, France. Phone: 33-1-42-49-92-60; Fax: 33-1-42-49-48-38; E-mail: Majid.Khatib@stlouis.inserm.fr.
1. Choti, M.A., and Bulkley, G.B. 1999. Management of hepatic metastases. Liver Transpl. Surg. 5:65-80.

2. Hiratsuka, M., et al. 2003. Management of patients with hepatic metastases from gastric carcinoma. Nippon Geka Gakkai Zasshi. 104:711-716.

3. Jaeck, D. 2003. The significance of hepatic pedicle lymph nodes metastases in surgical management of colorectal liver metastases and of other liver malignancies. Ann. Surg. Oncol. 10:1007-1011.

4. Vallet, C., Martinet, O., and Mosimann, F. 2001. Surgical treatment of hepatic metastases. Rev. Med. Suisse Romande. 121:119-124.

5. Kitakata, H., et al. 2002. Essential roles of tumor necrosis factor receptor p55 in liver metastasis of intrasplenic administration of colon 26 cells. Cancer Res. 62:6682-6687.

6. Khatib, A.M., et al. 1999. Rapid induction of cytokine and E-selectin expression in the liver in response to metastatic tumor cells. Cancer Res. 59:1356-1361.

7. Khatib, A.M., et al. 2005. Characterization of the host proinflammatory response to tumor cells during the initial stages of liver metastasis. Am. J. Pathol. 167:749-759.

8. Khatib, A.M., Fallavollita, L., Wancewicz, E.V., Monia, B.P., and Brodt, P. 2002. Inhibition of hepatic endothelial E-selectin expression by C-raf antisense oligonucleotides blocks colorectal carcinoma liver metastasis. Cancer Res. 62:5393-5398.

9. Kaleko, M., Rutter, W.J., and Miller, A.D. 1990. Overexpression of the human insulinlike growth factor I receptor promotes ligand-dependent neoplastic transformation. Mol. Cell. Biol. 10:464-473.

10. Reinmuth, N., et al. 2002. Impact of insulin-like growth factor receptor-I function on angiogenesis, growth, and metastasis of colon cancer. Lab. Invest. 82:1377-1389.

11. Wu, Y., Yakar, S., Zhao, L., Hennighausen, L., and LeRoith, D. 2002. Circulating insulin-like growth factor-I levels regulate colon cancer growth and metastasis. Cancer Res. 62:1030-1035.

12. Khatib, A.M., et al. 2001. Inhibition of proprotein convertases is associated with loss of growth and tumorigenicity of HT-29 human colon carcinoma cells: importance of insulin-like growth factor-1 (IGF-1) receptor processing in IGF-1-mediated functions. J. Biol. Chem. 276:30686-30693.

13. Grimberg, A. 2003. Mechanisms by which IGF-I may promote cancer. Cancer Biol. Ther. 2:630-635.

14. Bontemps, Y., Scamuffa, N., Calvo, F., and Khatib, A.M. 2007. Potential opportunity in the development of new therapeutic agents based on endogenous and exogenous inhibitors of the proprotein convertases. Med. Res. Rev. 27:631-648.

15. Khatib, A.M., Bassi, D., Siegfried, G., Klein-Szanto, A.J., and Ouafik, L. 2005. Endo/exo-proteolysis in neoplastic progression and metastasis. J. Mol. Med. 83:856-864.

16. Bassi, D.E., Fu, J., Lopez de Cicco, R., and KleinSzanto, A.J. 2005. Proprotein convertases: "master switches" in the regulation of tumor growth and progression. Mol. Carcinog. 44:151-161.

17. Tzimas, G.N., et al. 2005. Abnormal expression and processing of the proprotein convertases PC1 and PC2 in human colorectal liver metastases. BMC Cancer. 5:149.

18. Siegfried, G., Khatib, A.M., Benjannet, S., Chretien, M., and Seidah, N.G. 2003. The proteolytic processing of pro-platelet-derived growth factor-A at $\operatorname{RRKR}(86)$ by members of the proprotein conver- tase family is functionally correlated to plateletderived growth factor-A-induced functions and tumorigenicity. Cancer Res. 63:1458-1463.

19. Samani, A.A., Yakar, S., LeRoith, D., and Brodt, P. 2007. The role of the IGF system in cancer growth and metastasis: overview and recent insights. Endocr. Rev. 28:20-47.

20. Kim, C.S., et al. 2005. AKT activation promotes metastasis in a mouse model of follicular thyroid carcinoma. Endocrinology. 146:4456-4463.

21. Nakanishi, K., et al. 2002. Critical involvement of the phosphatidylinositol 3-kinase/Akt pathway in anchorage-independent growth and hematogeneous intrahepatic metastasis of liver cancer. Cancer Res. 62:2971-2975.

22. Culouscou, J.M., Remacle-Bonnet, M., Garrouste, F., Marvaldi, J., and Pommier, G. 1987. Simultaneous production of IGF-I and EGF competing growth factors by HT-29 human colon cancer line. Int. J. Cancer. 40:646-652.

23. Lahm, H., et al. 1994. Blockade of the insulin-like growth-factor-I receptor inhibits growth of human colorectal cancer cells: evidence of a functional IGF-II-mediated autocrine loop. Int. J. Cancer. 58:452-459.

24. Elbashir, S.M., et al. 2001. Duplexes of 21-nucleotide RNAs mediate RNA interference in cultured mammalian cells. Nature. 411:494-498.

25. Mantovani, A., Bussolino, F., and Introna, M. 1997. Cytokine regulation of endothelial cell function: from molecular level to the bedside. Immunol. Today. 18:231-240.

26. Simiantonaki, N., Jayasinghe, C., and Kirkpatrick, C.J. 2002. Effect of pro-inflammatory stimuli on tumor cell-mediated induction of endothelial 
cell adhesion molecules in vitro. Exp. Mol. Pathol. 73:46-53.

27. Siegfried, G., et al. 2003. The secretory proprotein convertases furin, PC5, and PC7 activate VEGF-C to induce tumorigenesis. J. Clin. Invest. 111:1723-1732.

28. Tozeren, A., et al. 1995. E-selectin-mediated dynamic interactions of breast- and colon-cancer cells with endothelial-cell monolayers. Int. J. Cancer. 60:426-431.

29. Brodt, P., et al. 1997. Liver endothelial E-selectin mediates carcinoma cell adhesion and promotes liver metastasis. Int. J. Cancer. 71:612-619.

30. Iwai, K., et al. 1993. Importance of E-selectin (ELAM-1) and sialyl Lewis(a) in the adhesion of pancreatic carcinoma cells to activated endothelium. Int. J. Cancer. 54:972-977.

31. Simiantonaki, N., Jayasinghe, C., and Kirkpatrick, C.J. 2002. Effect of pro-inflammatory stimuli on tumor cell-mediated induction of endothelial cell adhesion molecules in vitro. Exp. Mol. Pathol. 73:46-53.

32. Takeda, K., et al. 1991. Murine tumor cells metastasizing selectively in the liver: ability to produce hepatocyte-activating cytokines interleukin-1 and/ or -6. Jpn. J. Cancer Res. 82:1299-1308.

33. Salman, H., et al. 2000. Effect of colon carcinoma cell supernatants on cytokine production and phagocytic capacity. Cancer Lett. 159:197-203.

34. Kim, I., et al. 2001. VEGF stimulates expression of ICAM-1, VCAM-1 and E-selectin through nuclear factor-B activation in endothelial cells. J. Biol. Chem. 276:7614-7620.

35. Che, W., et al. 2002. Insulin-like growth factor-1 enhances inflammatory responses in endothelial cells: role of Gab1 and MEKK3 in TNF-alphainduced c-Jun and NF-kappaB activation and adhesion molecule expression. Circ. Res. 90:1222-1230.

36. Shankar, R., de la Motte, C.A., Poptic, E.J., and DiCorleto, P.E. 1994. Thrombin receptor-activating peptides differentially stimulate platelet-derived growth factor production, monocytic cell adhesion, and E-selectin expression in human umbilical vein endothelial cells. J. Biol. Chem. 269:13936-13941.

37. McCarron, R.M., Wang, L., Stanimirovic, D.B., and Spatz, M. 1993. Endothelin induction of adhesion molecule expression on human brain microvascular endothelial cells. Neurosci. Lett. 156:31-34.

38. Resnicoff, M., et al. 1994. Growth inhibition of human melanoma cells in nude mice by antisense strategies to the type 1 insulin-like growth factor receptor. Cancer Res. 54:4848-4850.

39. Burfeind, P., Chernicky, C.L., Rininsland, F., Ilan, J., and Ilan, J. 1996. Antisense RNA to the type I insulin-like growth factor receptor suppresses tumor growth and prevents invasion by rat prostate cancer cells in vivo. Proc. Natl. Acad. Sci. U. S. A. 93:7263-7268.

40. Pietrzkowski, Z., et al. 1993. Inhibition of growth of prostatic cancer cell lines by peptide analogues of insulin-like growth factor 1 . Cancer Res. 53:1102-1106.

41. Rininsland, F., et al. 1997. Suppression of insulinlike growth factor type I receptor by a triple-helix strategy inhibits IGF-I transcription and tumorigenic potential of rat C6 glioblastoma cells. Proc. Natl. Acad. Sci. U. S. A. 94:5854-5859.

42. Li, S.L., Liang, S.J., Guo, N., Wu, A.M., and Fujita-Yamaguchi, Y. 2000. Single-chain antibodies against human insulin-like growth factor I receptor: expression, purification, and effect on tumor growth. Cancer Immunol. Immunother. 49:243-252.

43. Qian, J., et al. 2007. Suppression of type 1 Insulinlike growth factor receptor expression by small interfering RNA inhibits A549 human lung cancer cell invasion in vitro and metastasis in xenograft nude mice. Acta. Biochim. Biophys. Sin. 39:137-147.

44. Grothey, A., et al. 1999. The role of insulin-like growth factor I and its receptor in cell growth, transformation, apoptosis, and chemoresistance in solid tumors. J. Cancer Res. Clin. Oncol. 125:166-173.

45. Peretz, S., Jensen, R., Baserga, R., and Glazer, P.M. 2001. ATM-dependent expression of the insulinlike growth factor-I receptor in a pathway regulating radiation response. Proc. Natl. Acad. Sci. U. S. A. 98:1676-1681.

46. Creemers, J.W., et al. 2006. Agouti-related protein is posttranslationally cleaved by proprotein convertase 1 to generate agouti-related protein (AGRP)83-132: interaction between AGRP83-132 and melanocortin receptors cannot be influenced by syndecan-3. Endocrinology. 147:1621-1631.

47. D’Anjou, F., et al. 2004. Silencing of SPC2 expression using an engineered delta ribozyme in the mouse betaTC-3 endocrine cell line. J. Biol. Chem. 279:14232-14239.

48. Villeneuve, P., et al. 2002. Altered processing of the neurotensin/neuromedin N precursor in PC2 knock down mice: a biochemical and immunohistochemical study. J. Neurochem. 82:783-793.

49. Scamuffa, N., Calvo, F., Chretien, M., Seidah, N.G., and Khatib, A.M. 2006. Proprotein convertases: lessons from knockouts. FASEB J. 20:1954-1963.

50. Duguay, S.J., Milewski, W.M., Young, B.D., Nakayama, K., and Steiner, D.F. 1997. Processing of wildtype and mutant proinsulin-like growth factor-IA by subtilisin-related proprotein convertases. J. Biol. Chem. 272:6663-6670.

51. Duguay, S.J., et al. 1998. Post-translational processing of the insulin-like growth factor-2 precursor. Analysis of O-glycosylation and endoproteolysis. J. Biol. Chem. 273:18443-18451.

52. Feldser, D., et al. 1999. Reciprocal positive regulation of hypoxia-inducible factor 1alpha and insulin-like growth factor 2. Cancer Res. 59:3915-3918.

53. Nejjari, M., et al. 2004. Inhibition of proprotein convertases enhances cell migration and metastases development of human colon carcinoma cells in a rat model. Am. J. Pathol. 164:1925-1933.

54. Wang, N., et al. 2006. The secretory leukocyte protease inhibitor is a type 1 insulin-like growth factor receptor-regulated protein that protects against liver metastasis by attenuating the host proinflammatory response. Cancer Res. 66:3062-3070.

55. López de Cicco, R., Bassi, D.E., Zucker, S., Seidah, N.G., and Klein-Szanto, A.J. 2005. Human carcinoma cell growth and invasiveness is impaired by the propeptide of the ubiquitous proprotein convertase furin. Cancer Res. 65:4162-4171.

56. Gu, M., Gordon, V.M., Fitzgerald, D.J., and Leppla, S.H. 1996. Furin regulates both the activation of Pseudomonas exotoxin A and the Quantity of the toxin receptor expressed on target cells. Infect. Immun. 64:524-527. 